\title{
Çok düşük doğum ağırlıklı prematürelerde antenatal magnezyum sülfat kullanımının patent duktus arteriozusa etkisi
}

\section{The effect of antenatal magnesium sulphate administration on patent ductus arteriozus in very low birth weight preterms}

\author{
Ufuk Çakır1 ${ }^{\mathbb{D}}$, Cüneyt Tayman'1
}

1SBÜ Zekai Tahir Burak Kadın Sağı̆̆ı Sağlık Uygulama ve Araştırma Merkezi, Yenidoğan Kliniği, ANKARA

\section{Öz.}

Amaç: Patent duktus arteriozus (PDA) sıklığı, gebelik haftası ve doğum ağırlığıyla ters orantılıdır ve birçok prematüre morbiditesine ve mortalitesine neden olabilir. Erken eyleminde tokolitik olarak kullanılan magnezyum sülfatın (MgSO4) PDA sıkıı̆ını artırdığıyla ilgili çelişkili sonuçlar vardır. Çalışmamızda çok düşük doğum ağırlıklı (ÇDDA; <1500g) prematürelerde antenatal MgSO4 uygulanmasının hemodinamik anlamlı PDA'nın (haPDA) üzerine etkisini belirlenmesi amaçlanmıştır.

Materyal ve metod: Çalışmamızda Ocak 2013 ile Aralık 2016 tarihleri arasında ünitemizde izlenen, ÇDDA bebekler retrospektif olarak incelendi. Bebeklerin demografik ve klinik özellikleri kayıt edildi. Çalışmaya dahil edilen prematürelerin haPDA'sı olan ve olmayanlar olarak iki gruba ayrılarak, demografik, klinik özellikleri ve MgSO4 uygulanması açından karşılaşıtııılı.

Bulgular: Toplam 602 ÇDDA bebeğin dahil edildiği çalışmamızda, 257 bebekte $(\% 42,7)$ haPDA saptandı ve 11 bebeğe $(\% 1,8)$ PDA ligasyonu uygulandı. Hemodinamik anlamlı PDA grubunda antenatal MgSO4 uygulanma oranı $\% 61,8(n=159)$, haPDA olmayan gruptaki antenatal MgSO4 uygulanma oranına \%31,6 $(n=109)$ göre istatistiksel olarak anlamlı yüksek olarak tespit edildi $(p<0,001)$.

Sonuç: Çalışmamızda ÇDDA'lı bebeklerde haPDA grubunda antenatal MgSO4 kullanım oranı ve prematüre morbiditeleri daha yüksek olarak bulundu.

Anahtar kelimeler: Patent duktus arteriozus, Prematüre, Çok düşük doğum ağırlığı, Magnezyum sülfat

\section{Abstract}

Background: The prevalence of patent ductus arteriosus (PDA) is inversely proportional to gestational age and birth weight, and may lead to many premature morbidities and mortality. There are contradictory results regarding the fact that magnesium sulphate (MgSO4), that is used as tocolytic in premature labor, increases the frequency of PDA. In our study, we aimed to determine the effect of antenatal MgSO4 application on haemodynamically significant PDA (hsPDA) in very low birth weight (VLBW; <1500g) premature infants.

Methods: We retrospectively evaluated the medical records of VLBW preterm infants with very low birth weight (VLBW; <1500g) between January 2013 and December 2016.The demographic and clinical characteristics of the infants were recorded. The preterms included in the study were divided into two groups as with hsPDA and without hsPDA. Demographic, clinical features and MgSO4 administration were compared between two groups.

Results: A total of 602 VLBW infans were included. 257 (42.7\%) infants had hsPDA, and 11 (1.8\%) infants with hsPDA had PDA ligation due to being unresponsive to medical treatment. The rate of administration of antenatal MgSO4 in the hsPDA group was $61.8 \%(n=159)$, and the rate of antenatal $\mathrm{MgSO} 4$ administration in the non-hsPDA group was found to be statistically significant $(31.6 \%)(n=109)$ $(p<0.001)$.

Conclusions: In our study, the rate of antenatal MgSO4 administration and premature morbidities were found to be higher in the hSPDA group than infants without hSPDA.

Keywords: Patent ductus arteriosus, Premature, Very low birth weight, Magnesium sulfate
Sorumlu Yazar I Corresponding Author

Dr. Ufuk ÇAKIR

SBÜ Zekai Tahir Burak Kadın Sağığı Sağlık Uygulama ve Araşıırma Merkezi, Yenidoğan Kliniği, Talatpaşa Bulvarı, Altındağ, ANKARA, Posta kodu: 06230

Tel: +90 5058581781

E-mail: drufukcakir@hotmail.com Geliş tarihi / Received: 17.10 .2018 Kabul tarihi / Accepted: 15.05.2019

Dol: 10.35440/hutfd.471717 


\section{Giriş}

Patent duktus arteriozus (PDA), respiratuvar distres sendromu (RDS), pulmoner kanama, uzamış ventilasyon destek süresi, bronkopulmoner displazi (BPD), prematüre retinopatisi (ROP), intraventriküler kanama (IVK), renal disfonksiyon, hipotansiyon, kalp yetmezliği, nekrotizan enterokolit (NEK), periventriküler lökomalazi (PVL), serebral palsi ve mortalite ile ilişkili önemli bir klinik problemdir (14). Patent duktus arteriozus sıklığı gebelik haftasıyla $(\mathrm{GH})$ ve doğum ağırlığı (DA) ters orantiııdır ve bundan dolayı prematürelerde daha sık olarak saptanmaktadır (5).

Magnezyum sülfat (MgSO4) prematüre doğum eylemlerinde, tokolitik olarak kullanılan bir ajandır. Magnezyum sülfat plasentayı pasif veya kolaylaştırımış transport ile geçer ve yeni doğan bebeklerde konsantrasyonu genellikle maternal seviyelerini aşar ve hipermagnezemiye yol açar, kordon konsantrasyonları anne seviyelerinden \% 70 -100'e kadar yükselebilir $(6,7)$.

Magnezyum sülfatın doğumdan sonra prematüre morbidite ve mortalitesi üzerine etkisi olabileceği tartışılmaktadır (69). Son yıllarda yapılan çalışmalarda, MgSO4'ün uzun dönemde nöroprotektif ve serebral palsiden koruyucu etkisi olduğu rapor edilmiştir (10-15). Magnezyum, vasküler tonun düzenlenmesinde önemli bir rol oynar. Magnezyum sülfat, kalsiyum iyon girişini düz kas hücrelerine antagonize eden ve böylece vazodilatasyona yol açan bir kalsiyum kanal blokörü olarak görev yapar. Hücre dışı magnezyum, vasküler kas hücrelerinin ve ayrıca endotel hücrelerinin hücre içi kalsiyum mobilizasyonunu ve prostoglandini etkiler. Her iki mekanizma da duktus arteriozusun gecikmiş kapanmasına katkıda bulunabilir (6). Bu amaçla yapılan çalışmalarda, antenatal MgSO4 uygulanması ve PDA arasındaki ilişki konusunda çelişkili sonuçlar vardır (6-9).

Çalışmamızda çok düşük doğum ağırlıklı (ÇDDA; <1500g) prematüre bebeklerde antenatal MgSO4 uygulanması ve hemodinamik anlamlı PDA (haPDA) arasındaki ilişkiye bakılması amaçlanmıştır.

\section{Materyal ve Metod Çalışma Tasarımı ve Hasta Seçimi Hastalar}

Çalışmamıza 1 Ocak 2013 ile 31 Aralık 2016 tarihleri arasında üçüncü düzey Eğitim ve Araştırma Hastanesi, Yenidoğan Yoğun Bakım Ünitesine (YYBÜ) yatan <1500 g prematüre bebekler dahil edildi. Major konjenital anomalisi olanlar ve ilk ekokardiyografik (EKO) değerlendirme öncesi kaybedilen hastalar çalışma dışı bırakıldı. Hastalar haPDA'sı olan (medikal ya da cerrahi ligasyon yapılan) ve haPDA'sı olmayanlar olarak iki gruba ayrıld. Klinik araştırmanın yapıldığı kurumdaki yerel etik kuruldan retrospektif çalışma onayı alındı. Çalışma Helsinki Illkeler Deklerasyonuna (www.wma.net/e/policy/b3.htm) uyularak gerçekleştirilmiştir. Ailelerden bilgilendirilmiş imzalı onam formu her hastanın YYBÜ'e kabulü sırasında alınmıştır.

\section{Çalışma protokolü}

Çalışmaya ait veriler retrospektif olarak hastane veri tabanından elde edildi. Ünitemizde ÇDDA'lı prematüre bebeklere, postnatal 3. ile 5. gün arasında, transtorasik EKO çocuk kardiyoloji uzmanı tarafından yapıldı. Ünite politikası gereği haPDA'sı olan hastalara ilk tercih olarak ibuprofen kullanıldı, siklooksijenaz inhibitörlerinin kullanılmasında kontrendikasyon varsa parasetamol tedavisi verildi. Üç kür medikal tedaviye rağmen haPDA olan hastalara cerrahi ligasyon yapıldı. Prematüre doğum eylemi olan gebe annelere MgSO4 verildi. Kadın doğum kliniğinde standart antenatal $\mathrm{MgSO} 4$ protokolü uygulanmış olup, antenatal MgSO4 ile tedavi edilen yenidoğanların annelerine, 6 gramlık 30 dakika boyunca infüzyon yükleme dozunun ardından, doğum zamanına kadar $2 \mathrm{~g} /$ saat'lik idame infüzyonu uygulanmıştır.

\section{Demografik ve klinik özellikler}

Gebelik haftası, DA, 1 ve 5. dakika Apgar skoru, cinsiyet, antenatal steroid uygulanması, RDS (sürfaktan ihtiyacı) (16), erken neonatal sepsis (ENS; postnatal illk 3 günde olan sepsis), geç neonatal sepsis (GNS; 4. ve sonraki günlerde olan kanıtlanmış veya klinik sepsis) (17), günlük sıvı artış miktarı (mL/kg/gün), invaziv ve non-invaziv solunum desteği ile oksijen destek süresi, BPD (orta/ağır) (18), lazer tedavisi gerektiren ROP (19), IVK (evre $\geq 3$ ) (20), NEK (evre $\geq 2$ ) (21), tam enteral beslenmeye geçiş günü, hastanede yatış süresi ve mortalite gibi demografik ve klinik özellikler kayıt edildi.

\section{Medikal ve cerrahi tedavi uygulaması}

İbuprofen kürü $10 \mathrm{mg} / \mathrm{kg}$ ilk doz, $5 \mathrm{mg} / \mathrm{kg}$ ardışık iki doz (toplam 3 gün) şeklinde verildi. Siklooksijenaz inhibitörlerinin kontrendikasyonu [kanıtlanmış ya da şüpheli sepsis, aktif kanama (özellikle intrakranial ya da gastrointestinal), trombositopeni $(<50.000 / \mathrm{mm} 3)$ veya koagülasyon bozukluğu, şüpheli ya da kesin NEK, renal yetmezlik (idrar çıkışı $<0,6 \mathrm{ml} / \mathrm{kg} / \mathrm{saat}$, kreatinin $>1,6 \mathrm{mg} / \mathrm{dl}$ )] varsa parasetamol verildi. Parasetamol kürü 60 mg/kg/gün, günlük 4 eşit dozda ardışık 3 gün şeklinde verildi (22). Üç kür medikal tedaviye rağmen haPDA olan hastalara cerrahi ligasyon uzman kardiyovasküler cerrah tarafından hasta başı yapıldı.

\section{İstatistik analiz}

Hastalardan elde edilen veriler bilgisayar ortamına aktarllarak sayısallaştııldı. İstatistiksel analizler, SPSS (Statistical Package for the Social Sciences) 16.0 istatistiksel Paket kullanılarak yapıldı. $P<0,05$ değeri istatistiksel açıdan anlamlı kabul edildi. Ölçüm değerlerinin normal dağılıma uygunlukları grafiksel olarak ve Shapiro- wilk testi ile incelendi. Sonuçlar ortalama \pm standart sapma veya ortanca (minimum-maksimum) olarak verildi. Sürekli değişkenler için bir $t$ testi veya Mann-Whitney $U$ testi uygulandı. Nominal değişkenler için $x 2$ testi veya Fisher exact testi uygulandı. 


\section{Bulgular}

Çalışmamızda 653 ÇDDA'lı prematüre bebek değerlendirildi. Çalışmadan dışlanma kriterlerine göre (ilk EKO yapımadan kaybedilen: 35 ve majör konjenital anomalisi olan 16) 51 prematüre bebek çalışmadan çıkarıldı. Toplam 602 ÇDDA prematüre bebeğin (GH: 28,1 \pm 1,2 hafta, DA: 1066 $\pm 227 \mathrm{~g}$ ) verileri değerlendirildi. Çok düşük doğum ağırlıklı prematürelerde haPDA oranı \%42,7 (257/602) ve PDA ligasyonu oranı \%1,8 (11/602) olarak bulundu. Hemodinamik anlamlı PDA grubunda antenatal MgSO4 uygulanma oranı $\% 61,8(n=159)$, haPDA olmayan grupta $\% 31,6$ $(n=109)$ olarak tespit edildi (Şekil 1).

Hemodinamik anlamlı PDA olan grubunda $\mathrm{GH}(27,7 \pm 1,1$ hafta), DA (1031 $\pm 224 \mathrm{~g})$ haPDA grubundaki GH $(28,2 \pm$ 1,2 hafta), DA'na (1073 $\pm 230 \mathrm{~g})$ göre istatistiksel olarak anlamlı düşük (sırasıyla; $p<0,001, p=0,02$ ) bulundu. Hemodinamik anlamlı PDA olan grupta RDS, GNS, ROP, IVK (evre $\geq 3$ ), orta-ağır BPD oranları anlamlı olarak yüksek bulundu $(p<0,05)$. Hemodinamik anlamlı PDA grubunda invaziv ve non-invaziv solunum desteği ile oksijen desteği ve hastanede kalış süresinin daha uzun olduğu, tam enteral beslenmeye geçiş zamanının daha geç olduğu bulundu $(p<0,05)$. Cinsiyet, 1. dakika ve 5 . dakika Apgar skorları, antenatal steroid, ENS, günlük SIVı artış miktarı (mL/kg/gün), NEK (evre $\geq 2$ ) ve mortalite oranları açısından haPDA olan ve olmayan gruplar arasında istatistiksel anlamlı fark saptanmadı $(p>0,05)$. Hemodinamik anlamlı PDA grubunda antenatal MgSO4 uygulanma oranı \%61,8 ( $n=159)$, haPDA olmayan gruptaki antenatal MgSO4 uygulanma oranına \%31,6 $(n=109)$ göre istatistiksel olarak anlamlı yüksek olarak tespit edildi $(p<0,001)$ (Tablo 1$)$.

Tablo 1. Demografik ve Klinik Özellikler

\begin{tabular}{|c|c|c|c|}
\hline & $\begin{array}{l}\text { Hemodinamik anlamlı olma- } \\
\text { yan PDA } \\
\text { ( } n=345 \text { ) }\end{array}$ & $\begin{array}{l}\text { Hemodinamik anlamlı PDA } \\
(n=257)\end{array}$ & $p$ \\
\hline Gebelik haftası, hafta* & $28,2 \pm 1,2$ & $27,7 \pm 1,1$ & $<0,001$ \\
\hline Doğum ağırlığı, gr* & $1073 \pm 230$ & $1031 \pm 224$ & 0,02 \\
\hline Erkek, n (\%) & $204(59)$ & $126(49)$ & 0,25 \\
\hline 1. dakika Apgar skoru, ortanca† & $5(1-7)$ & $5(1-7)$ & 0,06 \\
\hline 5. dakika Apgar skoru, $†$ & $8(2-9)$ & $7(3-9)$ & 0,09 \\
\hline Antenatal steroid, n (\%) & $196(56,8)$ & $140(54,5)$ & 0,42 \\
\hline RDS, n (\%) & $202(58)$ & $205(79,7)$ & $<0,001$ \\
\hline ENS, n (\%) & $75(21,7)$ & $46(17,9)$ & 0,60 \\
\hline Kanıtlanmış GNS, n (\%) & $83(23,6)$ & $83(33,1)$ & 0,01 \\
\hline Günlük sıvı artış miktarı (mL/kg/gün)* & $23,1 \pm 6,7$ & $21,4 \pm 6,8$ & 0,242 \\
\hline MV süresi, gün & $2,6 \pm 6,4$ & $6,5 \pm 10,5$ & $<0,001$ \\
\hline NSD süresi, gün* & $6,2 \pm 7,7$ & $11,2 \pm 10,9$ & $<0,001$ \\
\hline Oksijen desteği süresi, gün* & $11,4 \pm 12,9$ & $15,6 \pm 13,7$ & $<0,001$ \\
\hline Orta- Ağır BPD, n (\%) & $37(10,7)$ & $46(17,9)$ & 0,003 \\
\hline ROP, n (\%) & $51(14,7)$ & $62(24,1)$ & $<0,001$ \\
\hline IVK, Evre $\geq 3, \mathrm{n}(\%)$ & $26(7,5)$ & $39(15,1)$ & 0,003 \\
\hline NEK, Evre $\geq 2, n(\%)$ & $8(2,3)$ & $6(2,3)$ & 0,85 \\
\hline Tam enteral beslenme günü, gün* & $15,4 \pm 6,9$ & $17,3 \pm 6,7$ & $<0,001$ \\
\hline Hastanede yatış süresi, gün, $†$ & $51,7 \pm 29,1$ & $62,4 \pm 33,3$ & $<0,001$ \\
\hline Mortalite, $\mathrm{n}(\%)$ & $61(17,6)$ & $41(15,9)$ & 0,532 \\
\hline Antenatal MgSO4, n (\%) & $109(31,6)$ & $159(61,8)$ & $<0,001$ \\
\hline
\end{tabular}

*Ortalama \pm Standart sapma, (Mann-Whitney U test), †Ortanca (minumum-maksimum) (t test), \% (X² testi)

BPD: bronkopulmoner displazi, ENS: erken neonatal sepsis, GNS: geç neonatal sepsis, IVK: intraventiküler kanama, MgSO4: magnezyum sülfat, MV: mekanik ventilasyon, NSD: non invaziv solunum desteği, PDA: patent duktus arteriozus, RDS: respiratuvar distres sendromu, ROP: prematüre retinopatisi. 


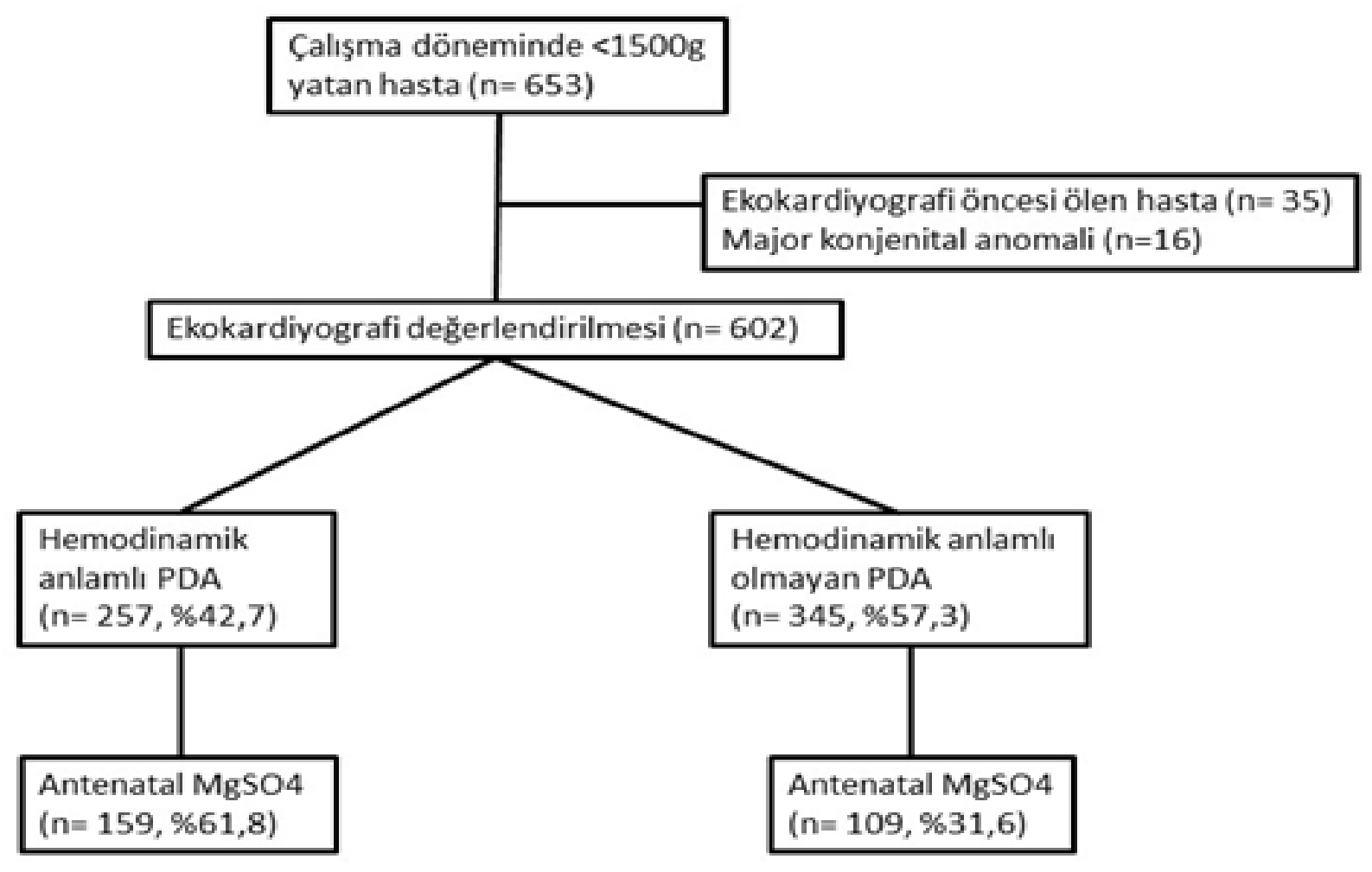

Şekil 1. Hemodinamik anlamlı olan ve olmayan PDA hastalarının antenatal MgSO4 uygulanma akış şeması MgSO4: magnezyum sülfat, PDA: patent duktus arteriozus

\section{Tartışma}

Çalışmamızda haPDA olan grupta, antenatal MgSO4 uygulanma, RDS, GNS, ROP, IVK ve orta-ağır BPD oranı yüksek, solunum destek, tam enteral beslenmeye geçiş ve hastanede yatış süresi daha uzun, GH ve DA daha düşük bulundu. Doğum haftası ve ağırlı̆ı azaldıkça PDA sıklığı arttığı çalışmamızda olduğu gibi genel olarak bilinmektedir $(5,23)$.

Çalışmamızda olduğu gibi özellikle GNS olmak üzere, sepsis PDA'nın kapanmasını geciktirmesi yanında, medikal tedaviye verilen yanıtı da azaltmaktadır $(24,25)$. Patent duktus arteriozus, mezenterik iskemi yaparak beslenme problemlerini beraberinde getirir, tam enteral geçiş gününü geciktirir ve NEK sıklığını artırabilir $(26,27)$. Sonuçlarımız, NEK dışında bu bilgileri desteklemektedir. Bunun sebebi tedavi günü ve rejimlerinin farklı olmasından dolayı olabilir. Surfaktan alan RDS hastaları sıklığı PDA kapanma oranını azalttığından, çalışmamızda olduğu gibi haPDA grubunda RDS oranı yüksektir (28). Patent duktus arteriozusun IVK, $\mathrm{BPD}, \mathrm{ROP}$ sıkıı̆ında, uzamış solunum desteği süresinde ve mortalite oranında artışla ilişkili olduğu bilinmektedir $(1,2,24,26)$. Bu verileri çalışmamız mortalite dışında desteklemektedir.

Antenatal MgSO4 ile tokoliz sıklıkla kullanılan ajandır $(6,7)$. Antenatal MgSO4, PDA dahil, birçok prematüre morbidite ve mortalite ile ilişkilendirilmiştir $(6-8,14)$. Aksini iddia eden çalışmalarda vardır (9,29). Ayrıca, yenidoğanda hipotansiyon, apne, gastrointestinal sistem motilitesinde azalma gibi yan etkilere neden olabilir $(11,30)$. Bu etkilerine rağmen nöroprotektif etkisi ve serebral palsi riskini azalması gibi olumlu etkileri de vardır (10-13,15). Antenatal MgSO4 hem tokolitik hem de nöroprotektif olarak uygulanmasında rağmen PDA sıkı̆̆ını artırabilmektedir. Çalışmamızın birincil amacı olan bu etkiye baktığımızda literatürdeki bazı rapor edilen çalışmalarda olduğu gibi antenatal MgSO4 haPDA sıklığını artırabilmektedir (6-8).

Magnezyumun, voltaj bağımlı kalsiyum kanalları üzerinden kas gevşetici ve vazodilatasyona neden olduğu gösterilmiştir (6). Bu etkiyle, kardiyovasküler sistem (PDA dahil) ve gastrointestinal sistem üzerinde yan etkilere neden olabilir. Antenatal MgSO4 dozu ve yenidoğanın serum düzeyi arttıkça, PDA sıkıı̆ı da dahil olumsuz etkileri artmaktadır $(6,8)$. Çalışmamamız retrospektif olmasından dolayı maternal uygulanan MgSO4'ün kaç doz alındığı ve süresi ile yenidoğanda ya da kord kanında magnezyum düzeyine bakılamamıştır. Erken doğum eylemi için MgSO4 dışındaki tedaviler ve erken doğum eylem sebepleri verilerine sahip olmamamız çalışmamızın kısıttııkları olarak düşünüldü. Sonuç olarak, prematürelerde birçok olumsuz sonuçlara neden olabilen PDA daha düşük $\mathrm{GH}$ ve DA bebekler yaşadıkça, halen önemli klinik problem olarak devam etmektedir. Hemodinamik anlamlı PDA için ana risk faktörü düşük 
GH ve DA iken hastaların prenatal, natal, postnatal risk faktörlerine ilaveten uygulanan ilaçlar haPDA ile ilişkili olabilir. Bu konuda randomize kontrollü çalışmalara intiyaç duymaktadır.

\section{Kaynaklar}

1. Prescott S, Keim-Malpass J. Patent Ductus Arteriosus in the Preterm Infant: Diagnostic and Treatment Options. Adv Neonatal Care. 2017; 17(1):10-18.

2. Bhat R, Das UG. Management of patent ductus arteriosus in premature infants. Indian J Pediatr. 2015; 82(1):53-60.

3. Hamrick SE, Hansmann G. Patent ductus arteriosus of the preterm infant. Pediatrics. 2010; 125(5):1020-30.

4. Halil H, Tayman C, Cakır U, Buyuktiryaki M, Serkant U, Oğuz SS. Serum Endocan Level as a Predictive Marker for Hemodynamically Significant Patent Ductus Arteriosus in Very Low Birth Weight Infants. Am J Perinatol. 2017; 34(13):1312-7.

5. Oncel MY, Erdeve O. Oral medications regarding their safety and efficacy in the management of patent ductus arteriosus. World $\mathrm{J}$ Clin Pediatr. 2016; 5(1):75-81.

6. del moral T, Gonzalez-Quintero VH, Claure N, Vanbuskirk S, Bancalari E. Antenatal exposure to magnesium sulfate and the incidence of patent ductus arteriosus in extremely low birth weight infants. J Perinatol. 2007; 27(3):154-7.

7. Katayama $\mathrm{Y}$, Minami H, Enomoto M, Takano $\mathrm{T}$, Hayashi S, Lee YK. Antenatal magnesium sulfate and the postnatal response of the ductus arteriosus to indomethacin in extremely preterm neonates. J Perinatol. 2011; 31(1):21-4.

8. Basu SK, Chickajajur V, Lopez V, Bhutada A, Pagala M, Rastogi S. Immediate clinical outcomes in preterm neonates receiving antenatal magnesium for neuroprotection. J Perinat Med. 2011; 40(2):185-9.

9. Elimian A, Verma R, Ogburn P, Wiencek V, Spitzer A, Quirk JG. Magnesium sulfate and neonatal outcomes of preterm neonates. J Matern Fetal Neonatal Med. 2002; 12(2):118-22.

10. Rouse DJ, Hirtz DG, Thom E, Varner MW, Spong CY, Mercer BM, et all. A randomized, controlled trial of magnesium sulfate for the prevention of cerebral palsy. N Engl J Med. 2008; 359(9):895-905.

11. Garg BD. Antenatal magnesium sulfate is beneficial or harmful in very preterm and extremely preterm neonates: a new insight. J Matern Fetal Neonatal Med. 2018: 1-7.

12. Huusom LD, Wolf HT. Antenatal magnesium sulfate treatment for women at risk of preterm birth is safe and might decrease the risk of cerebral palsy. BMJ Evid Based Med. 2018; 23(5):195-6.

13. Chollat C, Sentilhes L, Marret S. Fetal Neuroprotection by Magnesium Sulfate: From Translational Research to Clinical Application. Front Neurol. 2018; 9:247.

14. Diguisto C, Foix L'Helias L, Morgan AS, Ancel PY, Kayem G, Kaminski $M$, et all. Neonatal Outcomes in Extremely Preterm Newborns Admitted to Intensive Care after No Active Antenatal Management: A Population-Based Cohort Study. J Pediatr. 2018; pii: S0022-3476(18)31049-7.

15. Chollat C, Sentilhes L, Marret S. Protection of brain development by antenatal magnesium sulphate for infants born preterm. Dev Med Child Neurol. 2019; 61(1):25-30.

16. Dargaville PA, Gerber A, Johansson S, De Paoli AG, Kamlin CO, Orsini F, et al. Incidence and Outcome of CPAP Failure in Preterm Infants. Pediatrics. 2016; 138(1). pii: e20153985.

17. Leal YA, Álvarez-Nemegyei J, Lavadores-May Al, Girón-Carrillo $\mathrm{JL}$, Cedillo-Rivera R, Velazquez JR. Cytokine profile as diagnostic and prognostic factor in neonatal sepsis. J Matern Fetal Neonatal Med 2018; 1-7. doi: 10.1080/14767058.2018.

18. Walsh MC, Wilson-Costello D, Zadell A, Newman N, Fanaroff A. Safety, reliability, and validity of a physiologic definition of bronchopulmonary dysplasia. J Perinatol. 2003; 23(6):451-6.
19. International Committee for the Classification of Retinopathy of Prematurity. The International Classification of Retinopathy of Prematurity revisited. Arch Ophthalmol. 2005; 123(7):991-9.

20. Papile LA, Burstein J, Burstein R, Koffler H. Incidence and evolution of subependymal and intraventricular hemorrhage: a study of infants with birth weights less than 1,500 gm. J Pediatr. 1978; 92(4):529-34.

21. Bell MJ, Ternberg JL, Feigin RD, Keating JP, Marshall R, Barton $L$, et all. Neonatal necrotizing enterocolitis. Therapeutic decision based upon clinical staging. An Surg. 1978; 187(1):1-7.

22. Oncel MY, Yurttutan S, Erdeve O, Uras N, Altug N, Oguz SS, et al. Oral paracetamol versus oral ibuprofen in the management of patent ductus arteriosus in preterm infants: a randomized controlled trial. J Pediatr. 2014; 164(3):510-4.e1.

23. Moore P, Brook MM. Patent Ductus Arteriosus and aorticopulmonary window. İç: Moss and Adams' Heart Disease. Allen HD, Driscoll DJ, Shaddy RE, Feltes TF (eds). Wolters Kluwer- Lipincott Williams\& Wilkins, Philadelphia, ABD, 8. eds, 2013:722- 745.

24. Köksal N, Aygün C, Uras N. Türk Neonatoloji Derneği. Prematüre Bebekte Patent Duktus Arteriosus'a Yaklaşim Rehberi 2016.

25. Fowlie PW, Davis PG, McGuire W. Prophylactic intravenous indomethacin for preventing mortality and morbidity in preterm infants. Cochrane Database Syst Rev 2010; (7):CD000174.

26. Philips JB, Garcia-Pratz JA, Fulton DR, Kim MS. http://www.uptodate.com/contents/ management of patent ductus arteriosus in preterm infants.

27. Vick GW, Satterwhite C, Cassady G, Philips J, Yester MV, Logic JR. Radionuclide angiography in the evaluation of ductal shunts in preterm infants. J Pediatr. 1982; 101(2):264-8.

28. Clyman RI, Ballard PL, Sniderman S. Prenatal administration of betamethasone for prevention of patient ductus arteriosus. J Pediatr. 1981; 98(1):123-6.

29. Klauser CK, Briery CM, Keiser SD, Martin RW, Kosek MA, Morrison JC. Effect of antenatal tocolysis on neonatal outcomes. J Matern Fetal Neonatal Med. 2012; 25(12): 2778-81.

30. Edwards JM, Edwards LE, Swamy GK, Grotegut CA. Effect of Cord Blood Magnesium Level at Birth on Non-neurologic Neonatal Outcomes. Am J Perinatol. 2019; 36(1):3-7. 